\title{
An Inference System for Classifying Oil Palm Fungal Diseases
}

\author{
Olajide Blessing Olajide ${ }^{1}$, Odeniyi Olufemi Ayodeji ${ }^{2}$, Olabiyi Olatunji Coker ${ }^{3}$, Stephen Munu $^{4}$, \\ Yakubani Yakubu ${ }^{5}$ \\ ${ }^{1}$ Department of Computer Engineering, Federal University Wukari, Wukari, Nigeria. \\ ${ }^{2}$ Department of Computer Science, Osun State College of Technology, Esa Oke, Nigeria. \\ ${ }^{3}$ Department of Soil Science, Federal University Wukari, Wukari, Nigeria. \\ ${ }^{4,5}$ Department of Computer Science, Federal University Wukari, Wukari, Nigeria.
}

\begin{abstract}
:
The oil palm plant is one of the major important cash crops of the Nigerian economy and a significant contributor to the world market for vegetable oils. Unfortunately, infection with fungi has caused a decline in the productivity of oil palms and subsequently the palm oil industry. Hence the need to detect oil palm plant disease earlier before it affects it informed this research to develop a fuzzy inference model to predict the influence of fungal disease on the oil plant plants. Following extensive review of related works, the factors associated with the severity of fungal diseases in the oil palm plant were identified following validation by Botanist. Fuzzy triangular membership functions were used to formulate the input factors identified alongside the target variables for identifying the severity of fungal diseases affecting the oil palm plant. The rule base was formulated using IF-THEN statements to combine the values of the input factors with the respective values of the target severity of oil palm plant disease. The classification model for oil palm plant disease severity was simulated using the Fuzzy Logic Toolbox available in the MATLAB R2015b Software. The results showed that the developed inference system for oil palm plant was capable of classifying and predicting the degree of the fungal disease infection into four groups; no severity, low severity, moderate severity and high severity.
\end{abstract}

Key Words: oil palm; fungi; fuzzy logic; rules; triangular membership function and disease.

\section{Introduction}

The Oil Palm Plant (Elaeis guineensis jacq.) is one of the major important cash crops of the Nigerian economy. The palm oil industry has experienced rapid growth in recent decades, and has become a significant contributor to the world market for vegetable oils (Pacheco et al, 2017). The importance of oil palm to the national economy of Nigeria cannot be over emphasized. It ranges from production of food for human consumption, employment, income to farmers and nation and raw materials for industries. Oil palm which is a production of palm oil has been a major source of foreign exchange to Nigeria as well as source of revenue to major segment of the rural population of South East Nigeria (Onoh and Peter-Onoh, 2012). Unfortunately, infection with fungi has caused a decline in the productivity of oil palms and subsequently the palm oil industry, and created significant concern (Ekenta et al, 2017). It has been reported that the economic loss caused by this pathogen is up to 500 million US Dollars yearly (FAO, 2010). A wide variety of fungi can affect and decay all types of woody plants and trees by colonizing in wounds on trunks, branches and roots. The disease developed is commonly called wood rot disease (Ayodele and Eshalomi, 2010). or heartwood when it is limited to the center of older trees. Although the process may be very slow, it is estimated that the damage caused to timber trees by fungi, particularly in forests, is more than all other natural disasters combined, including insects and fire (David et al., 2008). The common practise for diseases identifications in plants in the field is the use of visual symptoms which an agricultural expert is able to map to certain diseases in the plant. For places where experts are not available, supplementary methods for carrying out field-based diagnoses are a critically required. Computational work in this area has been towards automating this process through building machine learning models that can take an image of a leaf 
and predict whether the plant is infected with a particular disease or not (Owomugisha et al., 2018). A significant viewpoint from this study is the prospect of detecting disease earlier before a diseased plant is characterised. This has implications in the timeliness and effectiveness of interventions that can be applied to the crops. As a result of this, soft computing techniques that adopt the use of inference rules generated for experts about the nature of crop diseases can be adopted for improving the detection rate of diseases affecting crops. Despite every system is prone to failure or slight of specification performance, fuzzy inference system over the years has proven to deliver services and predictions of higher efficacy with lesser failures recorded (Olajide et al, 2021).

Fuzzy logic is a qualitative computational strategy which describes uncertainty or partial truth. The approach produces a Fuzzy Inference System (FIS) which is a rule-based system used as a tool for representing different forms of knowledge about a problem. FIS is used for modelling the interactions and relationships that exists between its variables too improve predictability (Rizvi et al, 2020). FIS takes into account all the fuzzy rules in the rule base and learnt how to transform a fuzzified set of inputs to their corresponding fuzzified outputs as shown in Figure 1. There are four sub processes involved in FIS namely:

a. Fuzzification - this is the conversion of the crisp values assigned to the variables (both input and output) into their respective fuzzy logic linguistic variables defined by a mathematical model called a membership function;

b. Rule construction - Rule Definition which involved the identification of all the possible rules which explain the relationship between the values of input variables with respect to the value of the output variables using IF-THEN rules - provided based on the knowledge elicited from experts;

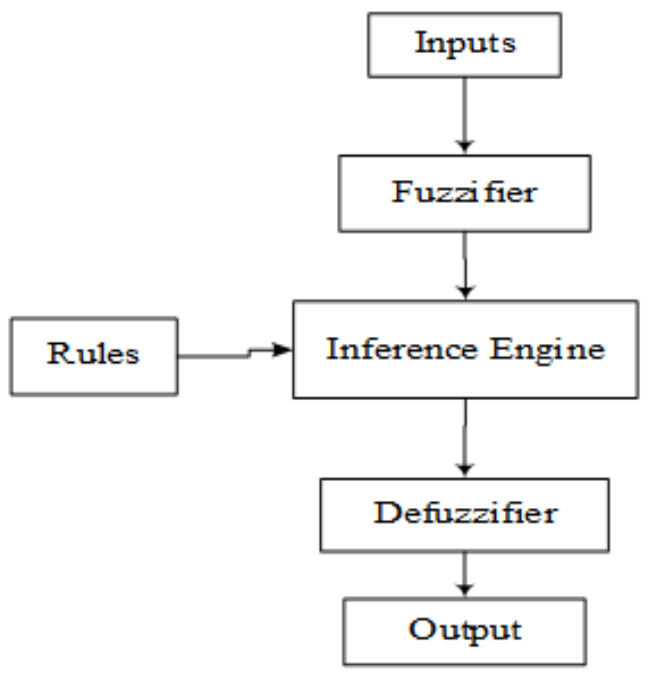

Figure 1: Schematic Diagram of a Fuzzy Inference System (Rizvi et al, 2020)

c. Combination of Fuzzy Rules - This involved the aggregation of all the fuzzified output mappings generated from the rules defined in the inference engine into a single fuzzified output map of linguistic value; and

d. Defuzzification - involves the conversion of the single output fuzzy linguistic values created by aggregation into the original crisp values of the output variable for determining the class to which the risk of post-partum hypertension is classified.

The fuzzy inference system also makes use of Membership Function (MF) which is a curve that defines how each point in the input space is mapped to a membership value (or degree of membership) between 0 and 1. The input space is sometimes referred to as the universe of discourse, a fancy name for a simple concept. The only condition a membership function must really satisfy is that it must vary between 0 and 1 . The function itself can be an arbitrary curve whose shape we can define as a function that suits us from the point of view of simplicity, convenience, speed, and efficiency. The membership function selected for this study is the triangular membership function. Hence the adoption of fuzzy logic for the formulation of the classification model for fungal diseases in oil palm plant will reduce the damage caused by fungal diseases which affect the oil palm plant thus mitigating the financial loss associated with the diseases. 


\section{Literature Review}

Bejo et al. (2019) developed a Basal Stem Rot disease detection model for oil palm plant using thermal imaging technique. Thermal images of canopy section of oil palm trees from healthy and BSR-infected trees were captured. The images were processed to extract pixel value representing thermal properties of the trees. These values were statistically analysed. Selected principal component scores were used in classification knearest neighbour (KNN) and Support Vector Machine (SVM) multivariate classification algorithms. The results demonstrated that when average pixel value of trees was used, the SVM-based model resulted in the highest average overall classification accuracy of $89.2 \%$ for training set and $84.4 \%$ for test set. The study was limited to the use of images for the classification of diseases affecting plants.

Ishaq et al. (2016), worked on the review of the detection of disease affecting plants based on images collected from plants upon observation. The study performed a literature review of study covering image processing of leaves, stem, branches and roots of plants using segmentation and filtering techniques. The results of the review showed that most of the techniques adopted include: removal of noise, segmentation, colour, texture and edge feature extraction of the affected area of the plant, and classification of diseases using classifiers. The study was limited to the review of image processing techniques adopted for disease detection in plants. Bejo et al, (2014), worked on the detection of basal Stem Rot diseases in Oil Palm Tree. This study examined the potential use of Terrestrial Laser Scanning (TLS) data to analyse the properties of oil palm tree at canopy and trunk section for non-infected and infected BSR at different severity level of infection. The results of the study showed that the area and perimeter at trunk section $150 \mathrm{~cm}$; and size of canopy shows significant relationship with the severity level of BSR with the Pearson correlation value of $0.571,-0.530$ and -0.806 , respectively. The study was limited to the detection of bacterial disease affecting the stem/trunk of Oil Palm Plants.

Suhartono et al. (2013) developed an expert system for detecting coffee plant diseases. The method used is fuzzy logic-based expert systems and decision tree using a hierarchical classification. Knowledge about coffee, its symptoms, and its disease was extracted from human expert and then converted into a decision tree. It resulted in the fuzzy logic-based expert systems. From the experiments, accuracy calculation of the system was about $85 \%$. Based on the accuracy, it was concluded that the application can assist researchers or observers of the coffee plants in diagnosing coffee plants diseases earlier. Olanloye and Yerokun (2018) developed an expert system for diagnosing poultry diseases. The study identified the factors that were required for assessing the presence of diseases among poultry animals from experts via interviews. The knowledge about the relationship between the factors was created using IF-THEN rules to create antecedent and consequent rules needed for the diagnosis of diseases among poultry. The expert system was designed using block diagrams following which it was implemented using the Visual Prolog software.

Kaur and Din (2016) developed a web-based expert system to detect and diagnose the leaf diseases of cereals in Punjabi Language. The features of leaf diseases were extracted and were used to formulate the diagnosis model by adopting IF-THEN rules from the features. The system was designed using unified modelling language (UML) tools such as use case diagrams and data flow diagrams. The model was integrated into a web-based implementation of the system using PHP and SQL. Awoyelu and Adebisi (2015) developed an expert's system for the diagnosis of cassava plant diseases. The study identified a number of symptoms that were taken from the leaves, stems and roots of cassava plant required for the diagnosis of 3 different cassava plant diseases. The study adopted the use of 3 triangular membership functions to formulate the 3 symptoms of each diseases identified alongside the level of disease risk. The Fuzzy Logic model was formulated using the MATLAB Fuzzy Logic Toolbox while the inference rules were constructed as IF-THEN statements combining the values of each identified symptom. The model recorded an accuracy of $71.4 \%$ during model validation.

\section{Methodology}

To develop the fuzzy logic-based model for the detection of fungal diseases in oil palm plant, variables relevant for detecting the severity of fungal disease in oil palm plant were identified with the help of a botanist. This stage was followed by formulation of classification model using the fuzzy membership functions. The inference engine for the fuzzy logic model was furnished by knowledge of the fungal diseases factors and variables of oil palm elicited from the botanist.

\subsection{Identification of Oil Palm Fungal Diseases}


Following an extensive review of related works and interview with expert botanists and agriculturists for the purpose of understanding the features relevant for the detection of oil palm plant fungal disease, nine features were identified alongside their respective labels. These variables were given different labels which were fuzzified using the triangular membership function with their respective crisp interval defined. The variables are presented alongside their respective labels as shown in Table 1.

Table 1: Identification of Crisp and Linguistic Values of Associated factors

\begin{tabular}{|c|c|c|}
\hline Associated factor & Linguistic Variable & Crisp Value \\
\hline Brownish-Gray colour on Leaves & $\begin{array}{l}\text { No } \\
\text { Yes }\end{array}$ & $\begin{array}{l}0 \\
1\end{array}$ \\
\hline Burnt-Orange Spot on Leaves & $\begin{array}{l}\text { No } \\
\text { Yes }\end{array}$ & $\begin{array}{l}0 \\
1\end{array}$ \\
\hline Whitish Skin-Like Layer on Stem-Base & $\begin{array}{l}\text { No } \\
\text { Yes }\end{array}$ & $\begin{array}{l}0 \\
1\end{array}$ \\
\hline Brownish Cortical Tissues & $\begin{array}{l}\text { No } \\
\text { Yes }\end{array}$ & $\begin{array}{l}0 \\
1\end{array}$ \\
\hline Pale Green Foliage & $\begin{array}{l}\text { No } \\
\text { Yes }\end{array}$ & $\begin{array}{l}0 \\
1\end{array}$ \\
\hline Dark-Brown Spear Rot & $\begin{array}{l}\text { No } \\
\text { Yes }\end{array}$ & $\begin{array}{l}0 \\
1\end{array}$ \\
\hline Seed-Rot & $\begin{array}{l}\text { No } \\
\text { Yes }\end{array}$ & $\begin{array}{l}0 \\
1\end{array}$ \\
\hline Presence of Infected Oil Palm Plant & $\begin{array}{l}\text { No } \\
\text { Yes }\end{array}$ & $\begin{array}{l}0 \\
1\end{array}$ \\
\hline Severity of Oil Palm Plant Fungal Disease & $\begin{array}{l}\text { None } \\
\text { Low } \\
\text { Moderate } \\
\text { High }\end{array}$ & $\begin{array}{l}0 \\
1 \\
2 \\
3 \\
\end{array}$ \\
\hline
\end{tabular}

\subsection{Fuzzification of variables}

For the purpose of developing a classification model for the severity of oil palm fungal diseases using fuzzy logic theory, each variables identified was fuzzified using a triangular membership function. The triangular membership function required the provision of 3 parameters which consisted of the left-hand base of triangle (a), the central apex of the triangle (b) and the right-hand base of the triangle (c). The values (a, b, c) of the triangular membership function corresponded to an interval of $\mathrm{a} \leq \mathrm{b} \leq \mathrm{c}$ such that the parameters are numeric valued. The interval of this parameter was used to define the crisp interval within which each crisp value required for calling the linguistic variable was assigned. As a result of this, since there were 2 or 4 linguistic variables defined for each factor identified then there were 2 (for identified features) or 4 (for severity of plant disease) triangular membership functions such that one was assigned to each linguistic variable identified for each associated factor as appropriate. Therefore, 2 triangular membership functions were formulated for each associated factor that was identified in this study based on the mathematical expression in equation (1). The expression shows how the triangular membership function was used to formulate the label of a variable called variable_label by fitting a numerical value $\mathrm{x}$ into a crisp interval of $(a, b, c)$.

$$
\text { Variable_label }(\mathrm{x} ; \mathrm{a}, \mathrm{b}, \mathrm{c})=\left\{\begin{array}{c}
0 ; \mathrm{x} \leq \mathrm{a} \\
\frac{\mathrm{x}-\mathrm{a}}{\mathrm{b}-\mathrm{a}} ; \mathrm{a}<x \leq \mathrm{b} \\
\frac{\mathrm{c}-\mathrm{x}}{\mathrm{c}-\mathrm{b}} ; \mathrm{b}<x \leq \mathrm{c} \\
0 ; \mathrm{x}>\mathrm{c}
\end{array}\right.
$$


Using 2 triangular membership functions, the labels of the identified associated factors were formulated using the crisp intervals of $(-0.5,0.5)$ and $(0.5,1.5)$ to model the linguistic variables for 0 and 1 respectively such that they are the center $b$ of each interval as shown in Table 2.

Table 2: Description of Crisp Intervals used during Fuzzy Model Formulation

\begin{tabular}{|l|l|l|l|l|}
\hline Crisp Value & Interval & A & B & C \\
\hline 0 & $(-0.5,0.5)$ & -0.5 & 0 & 0.5 \\
\hline 1 & $(0.5,1.5)$ & 0.5 & 1 & 1.5 \\
\hline
\end{tabular}

\subsection{Fuzzification of the severity of oil palm plant fungal disease}

Following the identification and the fuzzification of the associated features with detecting fungal disease in oil palm plant, there was a need to formulate the target variable that was used to define the severity of fungal disease. The triangular membership function was used to formulate the fuzzy logic model for the target variable by assigning crisp values of $0,1,2$ and 3to the target class labels, namely: No severity, Low severity, Moderate severity and High severity using the intervals $(-0.5,0.5),(0.5,1.5),(1.5,2.5)$ and $(2.5$, 3.5) respectively.

Therefore, four (4) triangular membership functions were used to formulate the fuzzy logic model required to describe the 4 labels of the target class that was used to detect the severity of fungal disease in oil palm plant using the identified crisp as shown in Table 3.3. Using the description provided in Table 3 , the relationship between the associated features and the severity of fungal disease in oil palm plant was proposed using the fuzzy inference system. The construction of the rule base used to design the fuzzy inference engine is presented in the following paragraphs.

Table 3: Formulation of the Severity of Fungal Disease in Oil Palm Plant

\begin{tabular}{|l|l|l|l|l|}
\hline Target Class & Interval & A & B & C \\
\hline No Risk & $(-0.5,0.5)$ & -0.5 & 0 & 0.5 \\
\hline Low Severity & $(0.5,1.5)$ & 0.5 & 1 & 1.5 \\
\hline Moderate Severity & $(1.5,2.5)$ & 1.5 & 2 & 2.5 \\
\hline High Severity & $(2.5,3.5)$ & 2.5 & 3 & 3.5 \\
\hline
\end{tabular}

\subsection{Fuzzy inference system design for Oil Palm Plant Fungal Disease}

Following the formulation of the fuzzy logic model using triangular membership functions to model the associated variables and fungal disease of the oil palm plant, the fuzzy inference engine was implemented. The fuzzy inference engine uses 256 IF-THEN rules by combining the associated factors as the precedence while the breast cancer survivals was used as the consequent variable. Using the associated factors that were identified for assessing the fungal diseases of oil palm plant, a typical rule that can be inferred is as follows:

IF(Brownish-Gray Leaves = "No") AND (Burnt-Orange Spot on Leaves = "No") AND (Whitish Skin-Like Layer on Stem Base = "No") AND (Brownish Cortical Tissues = "No") AND (Pale Green Foliage = "No") AND (Dark-Brown Spear Rot = "No") AND (Seed Rot = "No") AND (Presence of Infected Oil Pal Plant = "No") THEN (Severity of Oil Palm Plant Fungal Disease = "No Severity").

The 256 rules that were required to be formulated for the fuzzy model were estimated from the product of the number of linguistic variable for each variable. Therefore, since each of the factors considered has two linguistic variables each. Therefore, the total number of rules were $256\left(=2^{8}\right)$ rules.

\subsection{Oil Palm Disease Severity Classification Fuzzy Logic Model Simulation}

MATLAB is a high-performance language for technical computing. It integrates computation, visualization, and programming in an easy-to-use environment where problems and solutions are expressed in familiar mathematical notation. Toolboxes are comprehensive collections of MATLAB functions, commands and 
solvers that expand the MATLAB environment to solve particular classes of problems. Fuzzy Logic Toolbox ${ }^{\mathrm{TM}}$ provides MATLAB functions, graphical tools, and a Simulink* block for analysing, designing, and simulating systems based on fuzzy logic.

With respect to this study, there are five primary GUI tools (Elements of the MATLAB Fuzzy Logic System) for building, editing, and observing fuzzy inference systems in the toolbox.

i. Fuzzy Inference System (FIS) Editor; handles the high-level issues for the system: it was used to define the names and number of input and output variables for the proposed model. For this study, 8 input variables and 1 output variable were defined.

ii. Membership Function Editor; was used to define the shapes of all the membership functions associated with each variable. In this study, the triangular membership function was used to formulate all variables (input and output). For this study, 2 membership functions were used to formulate each input variable while 3 membership functions were used to formulate the output variable.

iii. Rule Editor; was used for editing the different rules that defined the behaviour of the system using a set of IF-THEN statements which combined the identified associated factors with the severity of oil palm plant fungal disease labels. The number of rules formulated was $2^{8}=256$ rules.

iv. Rule Vieweris; a MATLAB technical computing environment based display of the fuzzy inference diagram which was used as a diagnostic. It shows which rules are active, or how individual membership function shapes are influencing the results.

v. Surface Viewer; was used to display the dependency of one of the outputs on any one or two of the inputs. It was used to generate and plot an output surface map for the system.

\section{Simulation Results of Severity of Oil Plant Disease}

The results of the simulation of the model for the classification of the severity of oil palm plant disease is shown in Figure 2 such that the interval [-0.5, 0.5] with center 0 was used to model noseverity, $[0.5,1.5]$ with center 1 was used to model low severity, $[1.5,2.5]$ with center 2 was used to model moderate severity while [2.5, 3.5] with center 3 was used to model high severity. Figure 3 shows the screenshot of the final source code with a fis extension that was developed from the simulation of the development of the fuzzy logic model for the severity of oil palm plant fungal diseases. The .fis file including the system components describes the number of input, output, and the number of rules which is 256; followed by the variables' section which defines the name and number of membership functions alongside their types for each linguistic variables with their respective interval of crisp values.

\subsection{Simulation Result of Fuzzy Logic Model Classification of Severity of Oil Palm Plant Disease}

Figure 4 shows the process of importing the completed source file of the fuzzy model for the classification of the severity of fungal diseases affecting oil palm plant using the MATLAB Fuzzy Logic Toolbox. Figure 3 (above) shows the process of selecting the location of the fis file in the file directory which is the desktop as shown in Figure 4 (center). Figure 4 (below) shows the final fuzzy logic model displaying the seven input 


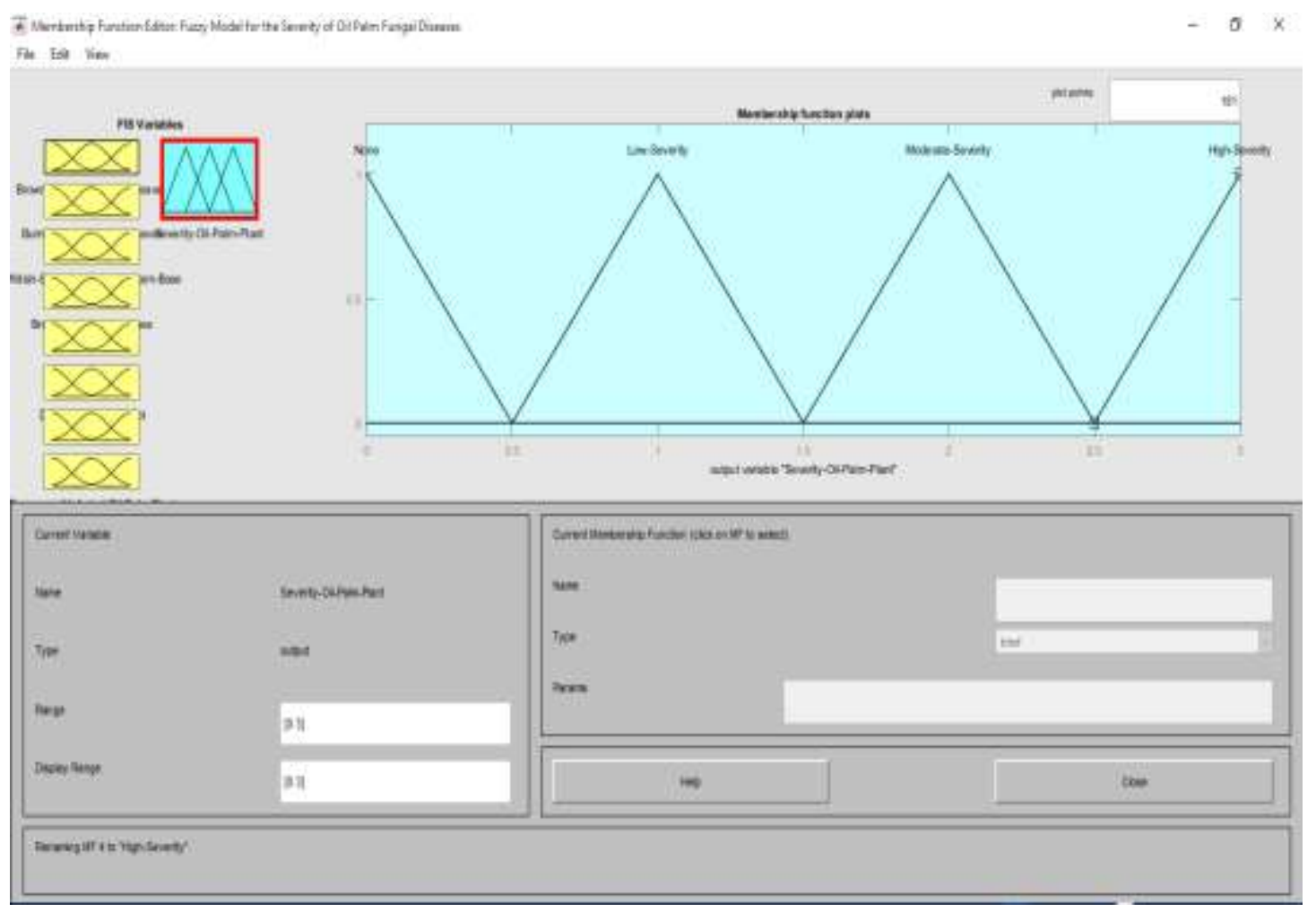

Figure 2: Fuzzification of Severity of Oil Palm Fungal Disease

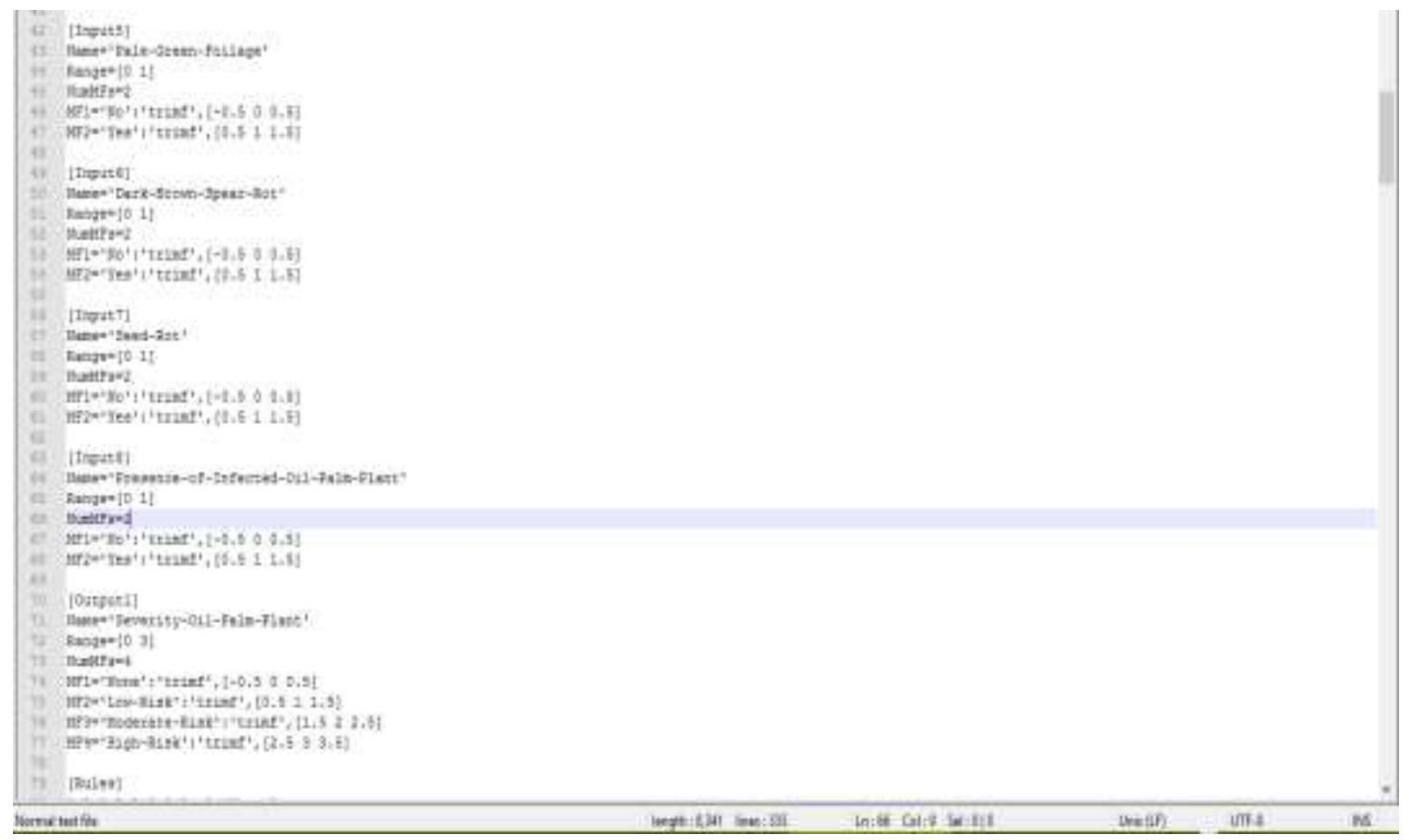

Figure 3: Source Code of Fuzzy Model for Severity of Oil Palm Plant Fungal Disease 


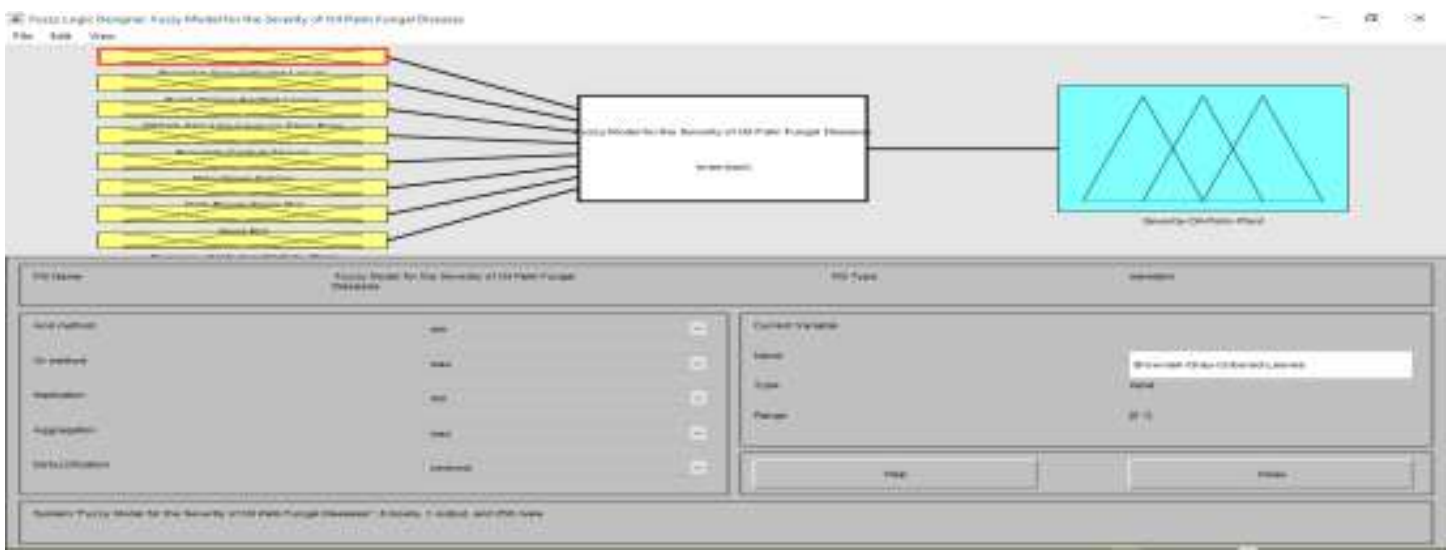

Figure 4: Importing .fis File for Classification of the Severity of Oil Palm Fungal Disease

variables and the output variable used to determine the classification of the severity of fungal diseases affecting oil palm plant. The 256 rules that were inferred for determining the classification of the severity of fungal diseases affecting oil palm plant were defined using the rule editor interface. Figure 5 shows the complete insertion of the 256 rules that were inferred for determining the classification of the severity of fungal diseases affecting oil palm plant. It is clear that each rule inferred is unique and does not contain linguistic variables occurring in the same pattern in any of the rules defined. Therefore, for any given set of rules $\mathrm{r}$ and $\mathrm{s}$ within the 256 rules there is no rule $\mathrm{r}$ that has the set of linguistic variables as another rule $\mathrm{s}$. Figure 6 displays the graphical region of each variable selected by each rule with respect to the linguistic variables of the classification of the severity of fungal diseases affecting oil palm plant.

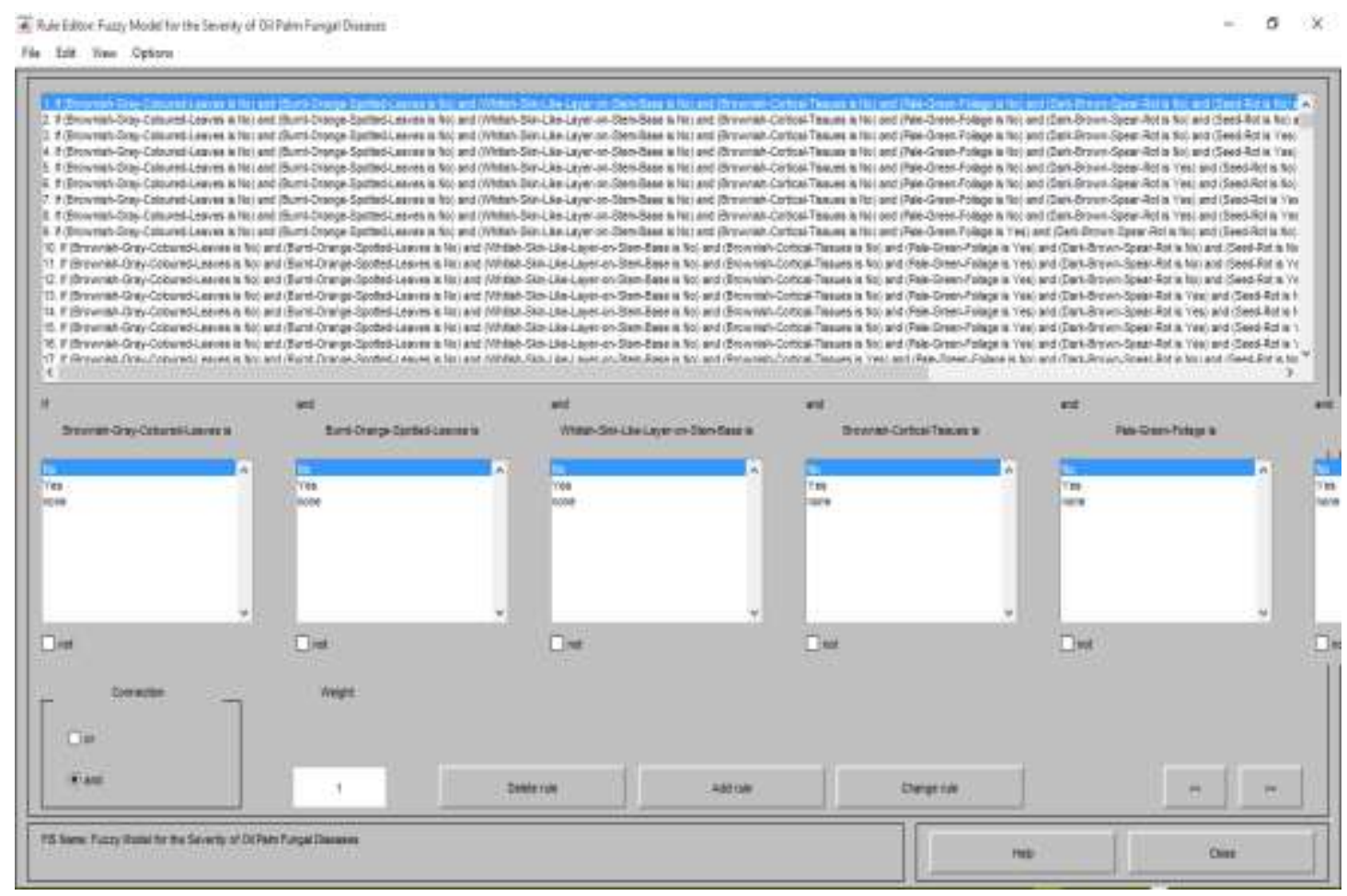

Figure 5: The Inferred Rules located in the Fuzzy Inference Engine

As shown in the bottom left part of the Figure 6, the crisp values entered were $0,1,1,0,0,1,1$ and 0 which were consistent with the linguistic values namely: no for presence of brownish-gray coloured leaves, yes for presence of burnt orange-spotted leaves, yes for presence of whitish skin-like layer on stem-base, no for presence of brownish cortical leaves, no for presence of pale green foliage, yes for presence of dark brown spear rot, yes for presence of seed rot and no for presence of infected oil palm plant. According to rule\# 102, the combination of these linguistic variables should have moderate classification of the severity of fungal 
diseases affecting oil palm plant which amounted to a crisp value of 2 which is within the interval of moderate.

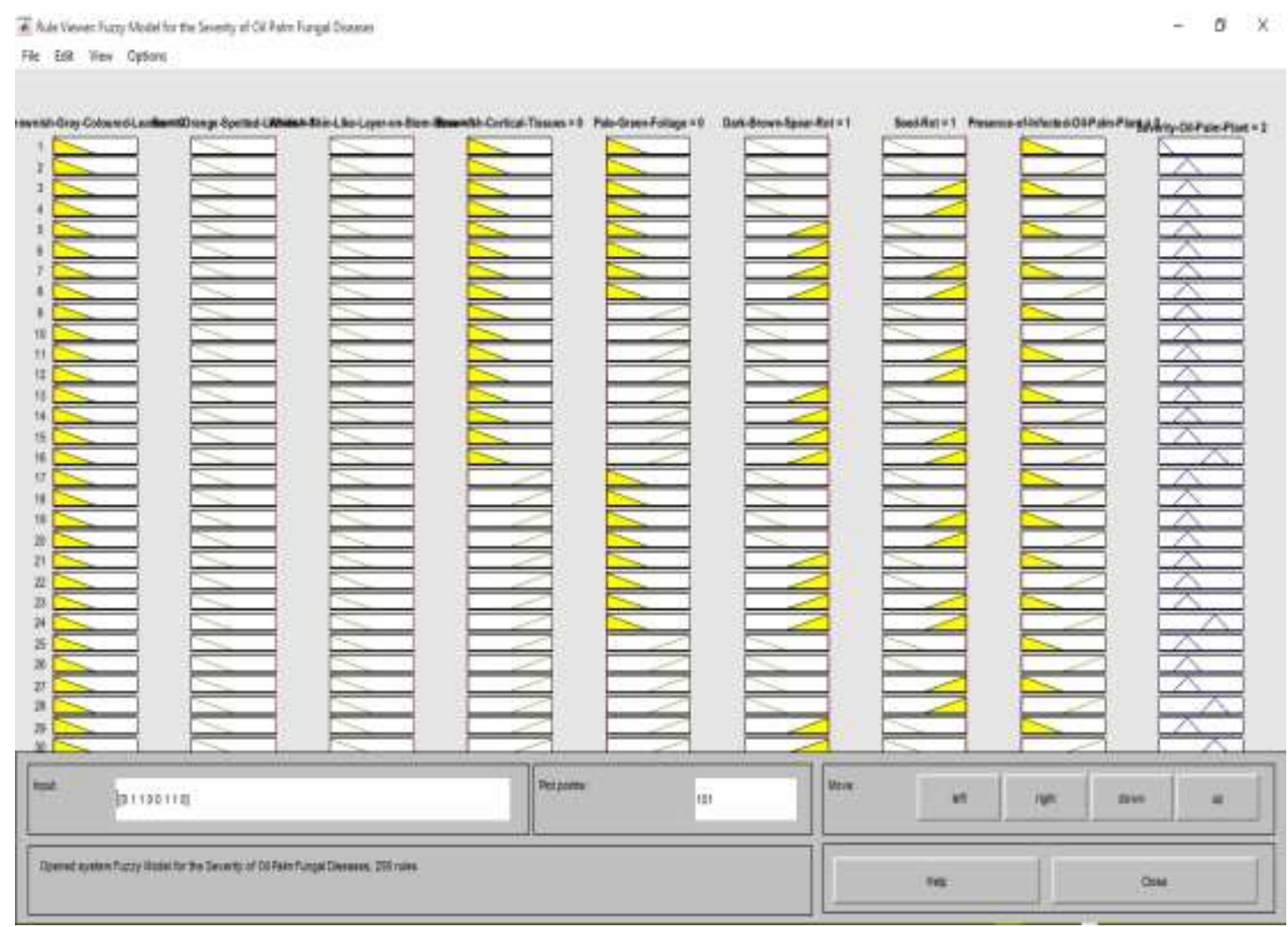

Figure 6: Testing the Validity of the Inference Engine

\subsection{Discussion of Results}

The study identified 8 risk factors required for the classification of the severity of oil palm plant disease. Each risk factor was defined using 2 linguistic variables for which central crisp values were assigned based on the association with the severity of oil palm plant disease. The higher the association of the linguistic variable then the higher the central crisp values assigned. The crisp values for each of the identified risk factor was done by allocating the values of 0 and 1 to linguistic variables namely: No and Yes respectively in increasing order of association with the severity of oil palm plant disease. Therefore, crisp intervals with centers of 0 and 1 were used to define the labels of the identified risk factor using triangular membership functions to identify labels in intervals [ $-0.50 .5]$ and [0.5 1.5$]$ respectively.

For the purpose of establishing a relationship between the identified risk factors identified, 256 rules were inferred from the experts in order to determine the relationship between the risk factors identified and the severity of oil palm plant disease. In order to construct the knowledge base of the classification model using fuzzy logic, a number of IF-THEN rules were used by combining the risk factors as the precedence while the severity of oil palm plant disease was used as the consequent variable. Using the risk factors that were identified for assessing the severity of oil palm plant disease, the process of inference rule generation was achieved.

\section{Conclusion}

This study developed a fuzzy inference model for the classification of the severity of fungal diseases affecting oil palm plant in order to determine the extent to which an oil palm plant was exposed to fungal diseases. This procedure provides an effective means for responding to the outbreak of fungal diseases amongst oil plants in order to mitigate further damage to neighbouring uninfected oil palm plants. This study concluded that based on the assessment of information about the presence or absence of associated features, the severity of fungal infections can be predicted.

This study recommends that additional efforts be put in place by botanists and agricultural scientist in the identification of other important factors that are associated with the fungal diseases alongside disease severity. This would improve the efficacy of the developed expert system. The study also recommends for 
future study that a web-based and mobile-based expert system be developed for facilitating the real-time observation and reporting of observations on-field.

\section{References}

1. Pacheco P, Gnych S, Dermawan A, Komarudin H and Okarda B. (2017): The palm oil global value chain: Implications for economic growth and social and environmental sustainability. Working Paper 220. Bogor, Indonesia: CIFOR

2. Onoh, P .A .and Peter-Onoh .C .A. (2012). Adoption of improved oil palm production technology among farmers in Aboh Mbaise local government area of Imo State. International Journal of Agriculture and Rural Development.15 (2), Pp. 966 -971

3. Ekenta, C. M., Ajala, M. K., Akinola, M.O. and Oseni, Y (2017): "Abandoned Nigerian Economic Resources: A Case of Oil Palm", International Journal of Agricultural Extension and Rural Development Studies, 4(2): 1-16.

4. FAO (2010): "Global forest resources assessment 2010", Food and Agriculture Organization of the United Nations. Rome, Italy.

5. Ayodele T. and Eshalomi M. O. (2010). African case study: Palm oil and economic development in Nigeria and Ghana. recommendations for the world bank's 2010 palm oil strategy. Initiative for Public Policy Analysis.

6. David L., Marco P. and Ottmar H. (2008): "Wood Decaying Fungi in the Forest: Conservation Needs and Management Options", European Journal of Forest Resources, 1-22.

7. Owomugisha G., Friedrich M., Ernest M., John A. And Michael B. (2018): "Machine Learning for Diagnosis of Disease in Plants Using Spectral Data", proceedings of International Conference of Artificial Intelligence, 9-15.

8. Olajide B. O., Oke A. O., Odeniyi O. A., Olabiyisi S. O. and Adeosun O. O. (2021): "An Approach to Improve the Availability of a Traffic Light System", International Journal of Intelligent Information System, DOI: 10. 11648/j.ijiis.20211004.11, Volume 10, Issue 4, pp37-43.

9. Rizvi S., John M., Abdul R., Mohammad R. R. and Iyonna W. (2020): “ A Fuzzy Inference System to Evaluate the Security Readiness of Cloud Service Providers", Journal of Cloud Computing, Systems and Applications, https://doi.org/10.1186/s13677-020-00192-9, 1-18.

10. Bejo S., Husin N., Ahmad F., Muhamad S., Mohd K., and Desa A. (2019): "Effect of Basal Stem Rot on Oil Palm Inter-frond Angles for Different Severity Levels", Journals of Advanced Agricultural Technologies 6(2): 113-117.

11. Ishaq I., Alias M., Kadir J., and Kasawani I. (2016): "Detection of basal stem rot disease at oil palm plantations using sonic tomography", Journal of Sustainability Science and Management, 9(2): 5257.

12. Suharto D. Wahhyu A. Miranty L and Muhammad Y. (2013): "Expert System in Detecting Coffee Plant Diseases", International Journal of Electrical Energy 1(3) 156-162.

13. Olanloye D. and Yerokun O. (2018): "Design and Implementation of an Expert System for Diagnosing, Treatment and Management of Poultry Disease", FULafia Journal of Science and Technology 4(2): 87-93.

14. Kaur R. And Din S. (2016): "Web Based Expert System to Detect and Diagnose the Leaf Disease of Cereals in Punjabi Language", International Journal of Computer Science and Information Technology 7(4) 1771-1773.

15. Awoyelu I. And Adebisi R. O. (2015): “A Predictive Fuzzy Expert System for Diagnosis of Cassava Plant Diseases", Global Journal of Science Frontier Research, 15(5): 20-28. 